\title{
Antimicrobial susceptibility patterns of unusual nonfermentative gram-negative bacilli isolated from Latin America: report from the SENTRY Antimicrobial Surveillance Program (1997-2002)
}

\author{
Ana C Gales/ ${ }^{+}$, Ronald N Jones*, Soraya S Andrade, Helio S Sader* \\ Disciplina de Doenças Infecciosas e Parasitárias, Departamento de Medicina, Universidade Federal de São Paulo, \\ Rua Leandro Dupret 188, 04025-010 São Paulo, SP, Brasil *The Jones Group/JMI Laboratories, North Liberty, IA, US
}

The antimicrobial susceptibility of 176 unusual non-fermentative gram-negative bacilli (NF-GNB) collected from Latin America region through the SENTRY Program between 1997 and 2002 was evaluated by broth microdilution according to the National Committee for Clinical Laboratory Standards (NCCLS) recommendations. Nearly $74 \%$ of the NF-BGN belonged to the following genera/species: Burkholderia spp. (83), Achromobacter spp. (25), Ralstonia pickettii (16), Alcaligenes spp. (12), and Cryseobacterium spp. (12). Generally, trimethoprim/sulfamethoxazole $\left(\right.$ MIC $_{50}$, $\leq 0.5 \mu \mathrm{g} / \mathrm{ml}$ ) was the most potent drug followed by levofloxacin $\left(M I C_{50}, 0.5 \mu \mathrm{g} / \mathrm{ml}\right)$, and gatifloxacin $\left(\mathrm{MIC}_{50}, 1 \mu \mathrm{g} / \mathrm{ml}\right)$. The highest susceptibility rates were observed for levofloxacin (78.3\%), gatifloxacin (75.6\%), and meropenem (72.6\%). Ceftazidime ( $\mathrm{MIC}_{50}, 4 \mu \mathrm{g} / \mathrm{ml} ; 83.1 \%$ susceptible) was the most active $\beta$-lactam against $\mathrm{B}$. cepacia. Against Achromobacter spp. isolates, meropenem (MIC ${ }_{50}, 0.25 \mu \mathrm{g} / \mathrm{ml}$; $88 \%$ susceptible) was more active than imipenem $\left(M^{2} C_{50}, 2\right.$ $\mu \mathrm{g} / \mathrm{ml})$. Cefepime $\left(\mathrm{MIC}_{50}, 2 \mu \mathrm{g} / \mathrm{ml} ; 81.3 \%\right.$ susceptible), and imipenem ( $M I C_{50}, 2 \mu \mathrm{g} / \mathrm{ml} ; 81.3 \%$ susceptible) were more active than ceftazidime (MIC $50,>16 \mu \mathrm{g} / \mathrm{ml}$; $18.8 \%$ susceptible) and meropenem (MIC ${ }_{50}, 8 \mu \mathrm{g} / \mathrm{ml}$; $50 \%$ susceptible) against Ralstonia pickettii. Since selection of the most appropriate antimicrobial agents for testing and reporting has not been established by the NCCLS for many of NF-GNB species, results from large multicenter studies may help to guide the best empiric therapy.

Key words: antimicrobial susceptibility - nonfermentative gram-negative -Latin America - SENTRY

Infections due to nonfermentative gram-negative bacilli (NF-GNB) other than Pseudomonas aeruginosa, Acinetobacter spp., and Stenotrophomonas maltophilia are uncommon but their incidence is increasing in the last years (Beringer \& Appleman 2000, Gales et al. 2001, Saiman et al. 2001). NF-GNB are inhabitants of soil and water and can colonize and cause infections mainly in im-munocompromised hosts. NF-GNB have mainly been implicated as a cause of nosocomial outbreaks associated with infusion of contaminated fluids, use of foreign devices and contaminated tap water (Roberts et al. 1990, Hsueh et al. 1996, Labarca et al. 1999, Sader \& Jones 2005).

Identification of some of these unusual NF-GNB is difficult and automated systems may fail in identifying some species (Van Pelt et al. 1999). In addition, the taxonomy of many NF-GNB has frequently changed. Decisions about performing susceptibility testing are further complicated by the fact that no interpretative breakpoints have been established for most of the unusual NF-GNB (NCCLS 2004). Furthermore, the results obtained with some organisms by the disk diffusion method do not correlate with those obtained by conventional MIC methods (Fraser \&

This study was presented in part at 43rd Interscience Conference on Antimicrobial Agents and Chemotherapy, Chicago, Illinois. September 14-17, 2003.

+Corresponding author. E-mail: galesac@aol.com

Received 30 March 2005

Accepted 26 August 2005
Jorgensen 1997, NCCLS 2004). Thus, clinical microbiology laboratories could face problems in identifying and susceptibility testing these pathogens.

We report the antimicrobial susceptibility profile of unusual NF-GNB isolated from the Latin American medical centers that participate in the SENTRY Antimicrobial Surveillance Program.

\section{MATERIALS AND METHODS}

Bacterial strains - A total of 176 unusual NF-GNB were collected from the Latin American region through the SENTRY Program between January 1997 and December 2002. The distribution of species is shown in Table I. The NF-GNB were isolated from blood (118), respiratory tract (44), wound (10), and urine (4). All strains were isolated from hospitalized patients and only a single isolate per patient was evaluated. The isolates were identified to the species level by the participant medical center using conventional biochemical tests and sent to the coordinating laboratory for identification confirmation and reference susceptibility testing. The identification confirmation was performed using the Vitek System (Hazelwood, MI) when necessary.

Medical centers - The participant medical centers were distributed throughout twelve cities in seven countries: Brasília (2001-2002), Florianópolis (1997-2002), Rio de Janeiro (1997-1998), São Paulo (1997-2002), and Porto Alegre (1999-2002) in Brazil; Buenos Aires (1997-2002) and San Isidro (1997-2002) in Argentina; Santiago in Chile (2 sites, 1997-2000); Medellin in Colombia (1997-2000); Mexico City in Mexico (3 sites, 1997-2002); Montevideo, Uruguay (1997); and Caracas in Venezuela (1998-2002). 
Susceptibility testing - Antimicrobial susceptibility testing was performed using the reference broth mi-crodilution method as described by the National Committee for Clinical Laboratory Standards (NCCLS 2003). The susceptibility and resistance rates were calculated according to the NCCLS breakpoints (M100-S14) established for testing non-Enterobacteriaceae isolates (NCCLS 2004). Antimicrobial agents were obtained from the respective manufacturers. Quality control was performed by testing Pseudomonas aeruginosa ATCC 27853, Escherichia coli ATCC 25922, Staphylococcus aureus ATCC 29213, and Enterococcus faecalis ATCC 29212.

\section{RESULTS AND DISCUSSION}

NF-GNB other than $P$. aeruginosa, Acinetobacter spp., and Stenotrophomonas maltophilia are uncommon pathogens; however, they represent a real challenge for the routine clinical microbiology laboratories since species identification is complex and antimicrobial susceptibility profile is unpredictable. Table I shows the frequency of occurrence of NF-GNB isolated from Latin American medical centers during the first six years of SENTRY program (1997-2002). B. cepacia (45.5\%) was the most frequently isolated NF-GNB, independent of the year of isolation, followed by Achromobacter xylosoxidans $(12.5 \%)$ and Ralstonia pickettii $(9.1 \%)$. Overall the Brazilian medical centers contributed with the largest number of strains (91 isolates; $51.7 \%$ ) followed by the Argentinean (32 isolates; 18.1\%) and Colombian (20 isolates, 11.4\%) medical centers. A single Brazilian medical center (number 048 ) provided $25 \%$ of the NF-GNB strains.

The distribution of the NF-GNB according to the site of infection is demonstrated in Table II. The majority $(67 \%)$ of NF-GNB strains were isolated from bloodstream infections. All pathogens were more frequently isolated from bloodstream infections with the exception of Cryseobacterium spp. and Alcaligenes spp. isolates. Cryseobacterium spp. strains were equally isolated from blood and respiratory tract infections, while Alcaligenes spp. strains were more frequently isolated from skin and soft tissue infections.

\section{TABLE I}

Frequency of occurrence of nonfermentative gram-negative bacilli isolated from Latin American medical centers (SENTRY Program, 1997-2002)

\begin{tabular}{lc}
\hline Organism & $\mathrm{n}(\%)$ \\
\hline Achromobacter spp. $^{a}$ & $25(14.2)$ \\
Alcaligenes spp. $^{b}$ & $12(6.8)$ \\
Burkholderia spp. $^{c}$ & $83(47.2)$ \\
Chryseobacterium spp. $^{d}$ & $12(6.8)$ \\
Comamonas acidovorans $_{\text {Ralstonia pickettii }}$ & $4(2.3)$ \\
Ochrobactrum antropi & $16(9.1)$ \\
Pseudomonas oryzihabitans & $8(4.5)$ \\
Others ${ }^{\text {e }}$ & $7(4.0)$ \\
Total & $9(5.1)$ \\
\hline
\end{tabular}

a: includes Achromobacter xylosoxidans (22) and Achromobacter spp. (3); $b$ : includes Alcaligenes faecalis (6) and Alcaligenes spp. (6); c: includes Burkholderia cepacia (80) and Burkholderia gladioli (3); $d$ : includes Chryseobacterium indologenes (6) and Chryseobacterium meningosepticum (6); e: includes Empedobacter brevi (2), Myroides odoratum (1), Ralstonia spp. (1), Sphingomonas paucimobilis (2), Sphingobacterium spp. (1), and other NF-GNB (2).

Antimicrobial susceptibility data on unusual NFGNB is very scarce (Gales et al. 2001, Jones et al. 2003, Sader \& Jones 2005). Changes in the nomenclature, use of disk-diffusion technique, and the isolation of low number of isolates make difficult to consider most of the published data. The most recent NCCLS documents do not include recommendations for the optimal antimicrobial susceptibility testing method for these NF-GNB, nor the antimicrobial agents that should be tested (NCCLS 2003, 2004). We tested a panel of antimicrobial agents with activity against gram-negative bacilli by broth microdilution and used susceptibility breakpoints established for nonEnterobacteriaceae to evaluate the antimicrobial susceptibility profile of uncommon NF-GNB isolated from Latin American centers through the SENTRY Program.

TABLE II

Distribution of the nonfermentative gram-negative bacilli according to the site of infection (SENTRY Program, Latin America 1997-2002)

\begin{tabular}{lcccc}
\hline Organism (N) & Blood N (\%) & Respiratory tract N (\%) & SST $^{a}$ N $(\%)$ & Urine N (\%) \\
\hline Achromobacter spp. $^{b}(25)$ & $16(64.0)$ & $8(32.0)$ & $1(4.0)$ & - \\
Alcaligenes spp. $^{c}(12)$ & $3(25.0)$ & $3(25.0)$ & $5(41.7)$ & $1(8.3)$ \\
Burkholderia spp. $^{d}(83)$ & $52(62.7)$ & $25(30.1)$ & $3(3.6)$ & $3(3.6)$ \\
Chryseobacterium spp. $^{e}(12)$ & $6(50.0)$ & $6(50.0)$ & $0(0.0)$ & $0(0.0)$ \\
Ralstonia pickettii $(16)_{\text {Others }}{ }^{(28)}$ & $16(100.0)$ & $0(0.0)$ & $0(0.0)$ & $0(0.0)$ \\
Total & $25(89.3)$ & $2(7.1)$ & $1(3.6)$ & $0(0.0)$ \\
\hline
\end{tabular}

$a$ : skin and soft tissue; $b$ : includes Achromobacter xylosoxidans (22) and Achromobacter spp. (3); : includes Alcaligenes faecalis (6) and Alcaligenes spp. (6); d: includes Burkholderia cepacia (80) and Burkholderia gladioli (3); e: includes Chryseobacterium indologenes (6); and Chryseobacterium meningosepticum (6); f: includes Comamonas acidovorans (4), Empedobacter brevi (2), Pseudomonas oryzihabitans (7), Myroides odoratum (1), Ralstonia spp. (1), Sphingomonas paucimobilis (2), Sphingobacterium spp. (1), and other NF-GNB (10). 
The in vitro activity of selected antimicrobial agents tested against the unusual NF-GNB isolated from the Latin American region is displayed in Table III. In general, the highest susceptibility rate was obtained with levofloxacin (78.3\% susceptible) followed by gatifloxacin $(75.6 \%)>$ meropenem $(72.6 \%)>$ imipenem $(69.9 \%)>$ trimethoprim/ sulfamethoxazole (68.6\%), and piperacillin/tazobactam $(67.4 \%)$. Although the fluoroquinolones had shown an identical in vitro potency $\left(\mathrm{MIC}_{50}, 1 \mathrm{mg} / \mathrm{ml}\right)$, ciprofloxacin showed the lowest susceptibility rate $(61.4 \%)$. The aminoglycosides, amikacin and gentamicin, demonstrated poor in vitro activity against NF-GNB inhibiting less than $30 \%$ of isolates at the susceptible breakpoints.

The antimicrobial activity of selected antimicrobial agents against the main genus of NF-GNB is shown in Table IV. With the exception of imipenem and meropenem that inhibited $100 \%$ of the Alcaligenes spp. isolates, none of the antimicrobial agents tested inhibited $100 \%$ of other NF-GNB genus.

Within the Burkholderia genus, B. cepacia complex represents the most important constituent as observed in this study. B. cepacia complex was subdivided by DNADNA hybridization, whole-cell protein pattern similarity, and phenotypic markers into five genomic species or genomovars, including $B$. multivorans (formerly genomovar II), B. stabilis (formerly genomovar IV), and B. vietnamiensis (formerly genomovar V). Genomovar III can be further subdivided into two groups on the basis of $r e c A$ sequences (groups IIIA and IIIB). More recently, four new members of the $B$. cepacia complex have been identified: genomovar VI, B. ambifaria (genomovar VII), B. pyrrocinia (genomovar IX), and B. anthina (genomovar VIII) (Detsika et al. 2003). The distinction of these genomic species is very difficult to achieve using only phenotypic tests. Thus, routine clinical microbiology laboratories will group these genomovars under a unique species named B. cepacia. B. cepacia complex isolates are intrinsically resistant to aminoglycosides and are often multidrug resistant (Beringer et al. 2000). Among Burkholderia spp. isolates, an important variation on the susceptibility rates of compounds belonging to the same class was noticed. Susceptibility rates varied from $79.5 \%$ for meropenem to $60.2 \%$ for imipenem, and from $83.1 \%$ for ceftazidime to $51.8 \%$ for cefepime. In this study, ceftazidime ( $\mathrm{MIC}_{50}, 4 \mu \mathrm{g} / \mathrm{ml} ; 83.1 \%$ susceptible) was the most active $\beta$-lactam against $B$. cepacia, in contrast to results reported by previous studies that showed meropenem as the most active $\beta$-lactam (Visalli et al. 1997, Bonacorsi et al. 1999). In addition, these studies also reported that trimethoprim/sulfamethoxazole was the most active non$\beta$-lactam drug. In the present study, levofloxacin $\left(\mathrm{MIC}_{50}\right.$, $1 \mu \mathrm{g} / \mathrm{ml} ; 81.9 \%$ susceptible and gatifloxacin $\left(\mathrm{MIC}_{50}, 1 \mu \mathrm{g} /\right.$ $\mathrm{ml} ; 79.5 \%$ susceptible) were more active than trimethop$\mathrm{rim} / \mathrm{sulfamethoxazole}\left(\mathrm{MIC}_{50}, \leq 0.5 \mu \mathrm{g} / \mathrm{ml} ; 71.1 \%\right.$ susceptible) against $B$. cepacia. These fluoroquinolones have shown good activity against Burkholderia spp. in previous studies (Biedenbach et al. 1999, Dawis et al. 2003).

Achromobacter xylosoxidans was briefly classified as genus Alcaligenes but was recently reclassified as Achromobacter (Yabuuchi et al. 1998). A. xylosoxidans infections have been reported in patients with HIV infec- tion, cancer, cystic fibrosis, transplant, as well as in neonates (Hearn \& Gander 1991, Dupon et al.1993, Dunne \& Maisch 1995, Manfredi et al. 1997, Hernandez et al. 1998). Reported case-fatality rates have varied from $3 \%$ for primary or catheter-associated bacteremia to $80 \%$ for neonatal infection (Duggan et al. 1996). Achromobacter strains are frequently resistant to aminoglycosides, ampicillin, first- and second-generation cephalosporins, and chloramphenicol, but are usually susceptible to antiPseudomonas third-generation cephalosporins, imipenem, and trimethoprim-sulfamethoxazole (Reverdy et al. 1984, Klinger \& Thomassen 1985, Mandell et al. 1987, Bizet et al. 1993). In the present study, 23 out of 25 Achromobacter isolates were identified as $A$. xylosoxidans. The car-bapenems were the most active antimicrobial drugs, especially meropenem $\left(\mathrm{MIC}_{50}, 0.25 \mu \mathrm{g} / \mathrm{ml} ; 88 \%\right.$ susceptible), which was four-fold more potent than imipenem ( $\mathrm{MIC}_{50}, 2 \mu \mathrm{g} / \mathrm{ml}$; $84 \%$ susceptible). In contrast, amikacin had poor activity against these isolates. Piperacillin/tazobactam $\left(\mathrm{MIC}_{50}\right.$, $1 \mu \mathrm{g} / \mathrm{ml} ; 76 \%$ susceptible) was also very active against Achromobacter spp. with susceptibility rate higher than that of trimethoprim/sulfamethoxazole $\left(\mathrm{MIC}_{50}, \leq 0.5 \mu \mathrm{g} /\right.$ $\mathrm{ml} ; 68 \%$ susceptible) and levofloxacin $\left(\mathrm{MIC}_{50}, 2 \mu \mathrm{g} / \mathrm{ml}\right.$; $68 \%$ susceptible). Our results are similar to those published by other investigators (Reverdy et al. 1984, Klinger \& Thomassen 1985, Mandell et al. 1987, Bizet et al. 1993, Saiman et al. 2001).

The genus Chryseobacterium, defined in 1994 by Vandamme et al., comprises six species, including $C$. meningosepticum (previously Flavobacterium menin-gosepticum) and C. indologenes (previously F. indologenes), which are the most common clinical species of this genus (Vandamme et al. 1994).

C. meningosepticum isolates are associated with meningitis in newborns or in immunocompromised patients, while $C$. indologenes is responsible mostly for nosocomial infections linked to the use of intravascular devices (Hsueh et al. 1996, Bloch et al. 1997). Chryseobacterium spp. isolates are intrinsically resistant to most $\beta$-lactams, including carbapenems, due to production of chromosomally encoded metallo- $\beta$-lactamases (Bellais et al. 2000 , Kirby et al. 2004). Among the $\beta$-lactams, only piperacillin and expanded-spectrum cephalosporins show in vitro activity against $C$. indologenes (Fraser \& Jorgensen 1997). Chryseobacterium spp. isolates are also resistant to aminoglycosides, tetracyclines, and chloramphenicol. All Chryseobacterium spp. isolates (12 strains) evaluated were resistant to imipenem and meropenem, and $75 \%$ of strains were also resistant to amikacin. Trimethoprim/sulfamethoxazole ( $\mathrm{MIC}_{50},>1 \mu \mathrm{g} / \mathrm{ml}$ ) was active against only $36.4 \%$ of Chryseobacterium spp. strains, and gatifloxacin $\left(\mathrm{MIC}_{50}, 0.5 \mu \mathrm{g} / \mathrm{ml}\right)$ and levofloxacin $\left(\mathrm{MIC}_{50}, 0.5 \mu \mathrm{g} / \mathrm{ml}\right)$ were the most active compounds ( $75 \%$ susceptible). As shown in a previous study, the fluoroquinolones seem to be the most effective antimicrobials against Chryseobacterium spp. (Kirby et al. 2004). However, the clinical use of the newer fluoroquinolones must be cautiously evaluated since therapeutic failure has been described with the use of ciprofloxacin (Gungor et al. 2003). Although vancomycin alone or in combination has been suggested as one of the therapeutic choices against $C$. meningosepticum infections 


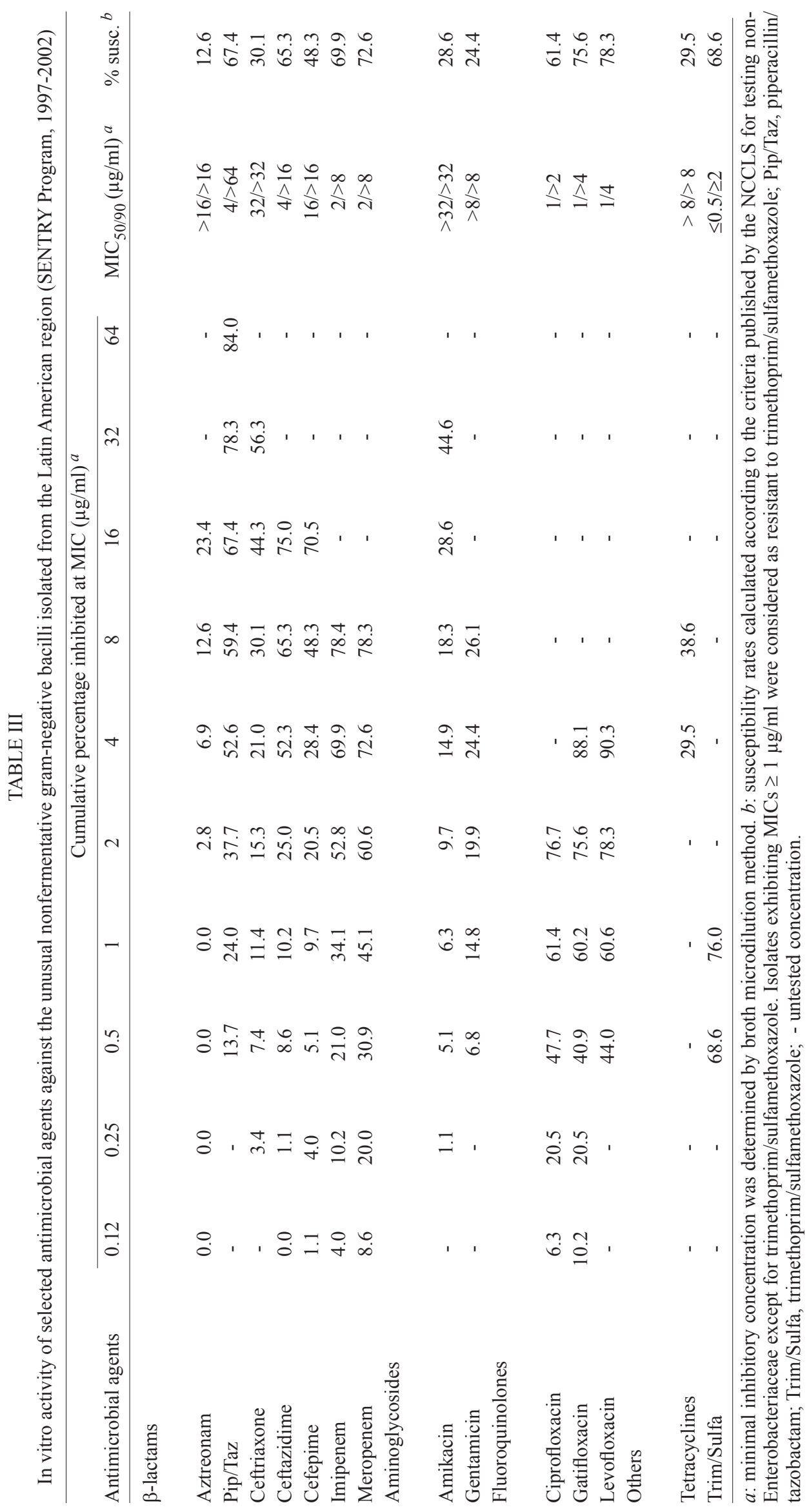


(Gungor et al. 2003), in vitro resistance has also been observed in more recent studies (Bloch et al. 1997, Fraser \& Jorgensen 1997, Kirby et al. 2004).

Ralstonia is a new genus that includes former members of Burkholderia species (B. pickettii and B. sola-nacearum), Alcaligenes eutrophus and CDC IVc-2 (Beringer et al. 2000). R. pickettii (formerly Pseudomonas picketti and B. pickettii) is a NF-GNB of relatively low virulence that can cause serious infections in im-munocompromised hosts (Beringer et al. 2000). Although outbreaks have been reported, it is often associated with pseudobacteremia or asymptomatic colonization of patients. Contamination of water supplies, skin disinfectants, and saline solutions used either for patient care or for laboratory diagnosis have been incriminated (Roberts et al. 1990, Luk 1996, Labarca et al. 1999). Previous studies have shown that usually $R$. picketti isolates are susceptible to trimethoprim/sulfamethoxazole (Fung-Tomc et al. 1997). However, $12.5 \%$ of the $R$. picketti isolated by the Latin American medical centers had trimethoprim/sulfamethoxazole MICs $\geq 1 \mu \mathrm{g} /$ $\mathrm{ml}$. The good activity of the ceftriaxone $\left(\mathrm{MIC}_{50}, 1 \mu \mathrm{g} / \mathrm{ml}\right.$; $87.5 \%$ susceptible), piperacillin/tazobactam ( $\mathrm{MIC}_{50}, 8$ $\mu \mathrm{g} / \mathrm{ml} ; 87.5 \%$ susceptible) and gatifloxacin $\left(\mathrm{MIC}_{50}, 0.25\right.$ $\mu \mathrm{g} / \mathrm{ml} ; 87.5 \%$ susceptible) observed in this study are in accordance with earlier studies (Fung-Tomc et al. 1997, Nordmann et al. 2000).

As more patients are rendered immunossupressed by chemotherapy, transplant or HIV infection, the increasing role of NF-GNB in hospital-acquired infections will be assured. Accurate identification of multiply antimicrobial-resistant gramnegative bacilli is critical to facilitate our understanding of the epidemiology of emerging pathogens. Furthermore, accurate identification and susceptibility testing of NF-GNB have important implications for patient treatment and guidance of infection control standards if patient-to-patient transmission is observed. In this context, surveillance programs such as the SENTRY Program, are very helpful by providing the most common susceptibility profile of these infrequent pathogens and, in this manner, guide the best empirical antimicrobial treatment of such infections.

\section{TABLE IV}

Antimicrobial activity of selected antimicrobial agents against the main genera of the nonfermentative gram-negative bacilli isolated in Latin America (SENTRY Program, 1997-2002)

\begin{tabular}{|c|c|c|c|c|}
\hline \multirow[b]{2}{*}{ Bacterial species/antimicrobial agent } & \multicolumn{3}{|c|}{$\operatorname{MIC}(\mu \mathrm{g} / \mathrm{ml})^{a}$} & \multirow[b]{2}{*}{$\%$ res. ${ }^{b}$} \\
\hline & $\mathrm{MIC}_{50}$ & $\mathrm{MIC}_{90}$ & $\%$ susc. $^{b}$ & \\
\hline \multicolumn{5}{|l|}{ Achromobacter spp. ${ }^{c}(25)$} \\
\hline Piperacillin/tazobactam & 1 & 64 & 76.0 & 8.0 \\
\hline Ceftazidime & 8 & $>16$ & 64.0 & 16.0 \\
\hline Cefepime & 16 & $>16$ & 24.0 & 36.0 \\
\hline Imipenem & 2 & 8 & 84.0 & 8.0 \\
\hline Meropenem & 0.25 & 8 & 88.0 & 4.0 \\
\hline Ciprofloxacin & 2 & $>2$ & 32.0 & 48.0 \\
\hline Gatifloxacin & 2 & $>4$ & 60.0 & 12.0 \\
\hline Levofloxacin & 2 & $>4$ & 68.0 & 16.0 \\
\hline Amikacin & $>32$ & $>32$ & 16.0 & 72.0 \\
\hline Trimethoprim/sulfamethoxazole & $\leq 0.5$ & $>2$ & 68.0 & 32.0 \\
\hline \multicolumn{5}{|l|}{ Alcaligenes spp. ${ }^{d}(12)$} \\
\hline Piperacillin/tazobactam & $\leq 0.5$ & 32 & 83.3 & 8.3 \\
\hline Ceftazidime & 4 & $>16$ & 75.0 & 25.0 \\
\hline Cefepime & 8 & $>16$ & 58.3 & 8.3 \\
\hline Imipenem & 1 & 2 & 100.0 & 0.0 \\
\hline Meropenem & 0.25 & 0.5 & 100.0 & 0.0 \\
\hline Ciprofloxacin & 1 & $>2$ & 58.3 & 25.0 \\
\hline Gatifloxacin & 1 & $>4$ & 66.7 & 25.0 \\
\hline Levofloxacin & 1 & $>4$ & 66.7 & 25.0 \\
\hline Amikacin & 16 & $>32$ & 50.0 & 41.7 \\
\hline Trimethoprim/sulfamethoxazole & $\leq 0.5$ & $>2$ & 66.7 & 33.3 \\
\hline \multicolumn{5}{|l|}{ Burkholderia spp..$^{e}(83)$} \\
\hline Piperacillin/tazobactam & 8 & 64 & 67.5 & 9.6 \\
\hline Ceftazidime & 4 & 16 & 83.1 & 6.0 \\
\hline Cefepime & 8 & $>16$ & 51.8 & 30.1 \\
\hline Imipenem & 4 & $>8$ & 60.2 & 26.5 \\
\hline Meropenem & 2 & $>8$ & 79.5 & 12.0 \\
\hline Ciprofloxacin & 1 & $>2$ & 61.4 & 18.1 \\
\hline Gatifloxacin & 1 & $>4$ & 79.5 & 10.8 \\
\hline Levofloxacin & 1 & 4 & 81.9 & 8.4 \\
\hline Amikacin & $>32$ & $>32$ & 18.1 & 60.2 \\
\hline Trimethoprim/sulfamethoxazole & $\leq 0.5$ & $>1$ & 71.1 & 28.9 \\
\hline
\end{tabular}




\begin{tabular}{|c|c|c|c|c|}
\hline \multirow[b]{2}{*}{ Bacterial species/antimicrobial agent } & \multicolumn{2}{|c|}{$\operatorname{MIC}(\mu \mathrm{g} / \mathrm{ml})^{a}$} & \multirow[b]{2}{*}{$\%$ susc. $^{b}$} & \multirow[b]{2}{*}{$\%$ res. ${ }^{b}$} \\
\hline & $\mathrm{MIC}_{50}$ & $\mathrm{MIC}_{90}$ & & \\
\hline \multicolumn{5}{|l|}{ Chryseobacterium spp. ${ }^{f}(12)$} \\
\hline Piperacillin/tazobactam & 4 & $>64$ & 58.3 & 25.0 \\
\hline Ceftazidime & $>16$ & $>16$ & 41.7 & 58.3 \\
\hline Cefepime & 16 & $>16$ & 41.7 & 41.7 \\
\hline Imipenem & $>8$ & $>8$ & 0.0 & 100.0 \\
\hline Meropenem & $>8$ & $>8$ & 0.0 & 100.0 \\
\hline Ciprofloxacin & 0.5 & $>2$ & 66.7 & 25.0 \\
\hline Gatifloxacin & 0.5 & $>4$ & 75.0 & 25.0 \\
\hline Levofloxacin & 0.5 & 4 & 75.0 & 0.0 \\
\hline Amikacin & $>32$ & $>32$ & 0.0 & 75.0 \\
\hline Trimethoprim/sulfamethoxazole & $>1$ & $>1$ & 36.4 & 63.6 \\
\hline \multicolumn{5}{|l|}{ Ralstonia pickettii (16) } \\
\hline Piperacillin/tazobactam & 8 & 32 & 87.5 & 6.3 \\
\hline Ceftriaxone & 1 & $>32$ & 87.5 & 12.5 \\
\hline Ceftazidime & $>16$ & $>16$ & 18.8 & 62.5 \\
\hline Cefepime & 2 & $>16$ & 81.3 & 18.8 \\
\hline Imipenem & 2 & 8 & 81.3 & 6.3 \\
\hline Meropenem & 8 & $>8$ & 43.8 & 50.0 \\
\hline Ciprofloxacin & 0.25 & $>2$ & 81.3 & 12.5 \\
\hline Gatifloxacin & 0.25 & 4 & 87.5 & 6.3 \\
\hline Levofloxacin & $\leq 0.5$ & 4 & 81.3 & 6.3 \\
\hline Amikacin & 16 & $>32$ & 56.3 & 31.3 \\
\hline Tetracycline & $\leq 4$ & $>8$ & 68.8 & 18.8 \\
\hline Trimethoprim/sulfamethoxazole & $\leq 0.5$ & $>1$ & 87.5 & 12.5 \\
\hline
\end{tabular}

$a$ : minimal inhibitory concentration was determined by broth microdilution method; $b$ : susceptibility rates calculated according to the criteria published by the NCCLS for testing non-Enterobacteriaceae except for trimethoprim/sulfamethoxazole. Isolates exhibiting MICs $\geq 1 \mu \mathrm{g} / \mathrm{ml}$ were considered as resistant to trimethoprim/sulfamethoxazole; $c$ : includes Achromobacter xylosidans (22) and Achromobacter spp. (3); $d$ : includes Alcaligenes faecalis (6) and Alcaligenes spp. (6); e: includes Burkholderia cepacia (80) and Burkholderia gladioli (3); $f$ : includes Chryseobacterium indologenes (6) and Chryseobacterium meningosepticum (6).

\section{ACKNOWLEDGMENTS}

To all medical technicians who have worked in SENTRY. The SENTRY Antimicrobial Surveillance Program has been sponsored by a research/educational grant from Bristol-Myers Squibb. The SENTRY Latin American Study Group 1997-2002 includes: Helio S Sader and Ana C Gales (São Paulo, Brazil - Latin America Coordinators); Cássia Zoccoli (Laboratório Médico Santa Luzia, Florianópolis, Brazil); Jorge Sampaio (Laboratório Lâmina, Rio de Janeiro, Brazil; 1997-1998); Afonso Barth (Hospital de Clínicas, Porto Alegre, Brazil; 1999-2002); Julival Ribeiro (Hospital de Base, Brasília, Brazil; 2001-2002); José M Casellas (Centro de Estudios en Antimicrobianos, San Isidro, Argentina); Jorgelina Smayevsky (Laboratorio CEMIC, Buenos Aires, Argentina); Valeria Prado (Facultad de Medicina de Chile, Santiago, Chile); Elizabeth Palavecino/Patricia Garcia (Universidad Católica del Chile, Santiago, Chile); Jaime A Robledo (Corporación Para Investigaciones Biológicas, Medellín, Colombia;1997-2000); José Sifuentes-Osornio (Instituto Nacional de la Nutrición, Ciudad del México, México); Homero Bagnulo (Hospital Maciel, Montevideo, Uruguay; 1997); and Manuel Guzmán-Blanco (Hospital Vargas, Caracas, Venezuela; 1998-2002).

\section{REFERENCES}

Bellais S, Poirel L, Leotard S, Naas T, Nordmann P 2000. Genetic diversity of carbapenem-hydrolyzing metallo-beta-lactamases from Chryseobacterium (Flavobacterium) indologenes. Antimicrob Agents Chemother 44: 3028-3034.

Beringer PM, Appleman MD 2000. Unusual respiratory bacterial flora in cystic fibrosis: microbiologic and clinical features. Curr Opin Pulm Med 6: 545-550.
Biedenbach DJ, Croco MA, Barrett TJ, Jones RN 1999. Comparative in vitro activity of gatifloxacin against Ste-notrophomonas maltophilia and Burkholderia species isolates including evaluation of disk diffusion and E test methods. Eur J Clin Microbiol Infect Dis 18: 428-431.

Bizet C, Tekaia F, Philippon A 1993. In-vitro susceptibility of Alcaligenes faecalis compared with those of other Alcaligenes spp. to antimicrobial agents including seven beta-lactams. $J$ Antimicrob Chemother 32: 907-910.

Bloch KC, Nadarajah R, Jacobs R 1997. Chryseobacterium meningosepticum: an emerging pathogen among immunocompromised adults. Medicine 76: 30-41.

Bonacorsi S, Fitoussi F, Lhopital S, Bingen E 1999. Comparative in vitro activities of meropenem, imipenem, temocillin, piperacillin, and ceftazidime in combination with tobramycin, rifampin or ciprofloxacin against Burkholde-ria cepacia isolates from patients with cystic fibrosis. Antimicrob Agents Chemother 43: 213-217.

Dawis MA, Isenberg HD, France KA, Jenkins SG 2003. In vitro activity of gatifloxacin alone and in combination with cefepime, meropenem, piperacillin and gentamicin against multidrug-resistant organisms J Antimicrob Chemother 51: 1203-211.

Detsika MG, Corkill JE, Magalhães M, Glendinning KJ, Hart CA, Winstanley C 2003. Molecular typing of, and distribution of genetic markers among Burkholderia cepacia complex isolates from Brazil. J Clin Microbiol 41: 4148-4153.

Duggan JM, Goldstein SJ, Chenoweth CE, Kauffman CA, Bradley SF 1996. Achromobacter xylosoxidans bacteremia: 
report of four cases and review of the literature. Clin Infect Dis 23: 569-576.

Dunne WM, Maisch S 1995. Epidemiological investigation of infections due to Alcaligenes species in children and patients with cystic fibrosis: use of repetitive-element-sequence polymerase chain reaction. Clin Infect Dis 20: 836-841.

Dupon M, Winnock S, Rogues AM, Janvier G, de Barbeyrac B, Saric J 1993. Achromobacter xylosoxidans (Alcaligenes xylosoxidans subspecies xylosoxidans) bacteremia after liver transplantation. Intensive Care Med 19: 480.

Fraser SL, Jorgensen JH 1997. Reappraisal of the antimicrobial susceptibilities of Chryseobacterium and Flavobacterium species and methods for reliable susceptibility testing. Antimicrob Agents Chemother 41: 2738-2741.

Fung-Tomc J, Bush K, Minassian B, Kolek B, Flamm R, Gradelski E, Bonner D 1997. Antimicrobial activity of BMS-180680, a new catechol-containing monobactam. Antimicrob Agents Chemother 41: 1010-1016.

Gales AC, Jones RN, Forward KR, Linares J, Sader HS, Verhoef J 2001. Emerging importance of multidrug-resistant Acinetobacter species and Stenotrophomonas maltophilia as pathogens in seriously ill patients: geographic patterns, epidemiological features, and trends in the SENTRY Antimicrobial Surveillance Program (1997-1999). Clin Infect Dis; 32(Suppl. 2): S104-113.

Gungor S, Ozen M, Akinci A, Durmaz R 2003. A Chry-seobacterium meningosepticum outbreak in a neonatal ward. Infect Control Hosp Epidemiol 24: 613-617.

Hearn YR, Gander RM 1991. Achromobacter xylosoxidans: an unusual neonatal pathogen. Am J Clin Pathol 96: 211-214.

Hernandez JA, Martino R, Pericas R, Sureda A, Brunet S, Domingo-Albos A 1998. Achromobacter xylosoxidans bacteremia in patients with hematologic malignancies. Haematologica 83: $284-285$.

Hsueh PR, Teng LJ, Ho SW, Hsieh WC, Luh KT 1996. Clinical and microbiological characteristics of Flavobacterium indologenes infections associated with indwelling devices. J Clin Microbiol 34: 1908-913.

Jones RN, Sader HS, Beach ML 2003. Contemporary in vitro spectrum of activity summary for antimicrobial agents tested against non-fermentative gram-negative bacilli $(18,569$ strains) isoalted in the SENTRY Antimicrobial Surveillance Program (1997-2001). Int J Antimicrob Agents 22: 551-556.

Kirby JT, Sader HS, Walsh TR, Jones RN 2004. Antimicrobial susceptibility and epidemiology of a worldwide collection of Chryseobacterium spp: report from the SENTRY Antimicrobial Surveillance Program (1997-2001). J Clin Microbiol 42: 445-448.

Klinger JD, Thomassen MJ 1985. Occurrence and antimicrobial susceptibility of gram-negative nonfermentative bacilli in cystic fibrosis patients. Diagn Microbiol Infect Dis 3: 149-158.

Labarca JA, Trick WE, Peterson CL, Carson LA, Holt SC, Arduino MJ, Meylan M, Mascola L, Jarvis WR 1999. A multistate nosocomial outbreak of Ralstonia pickettii colonization associated with an intrinsically contaminated respiratory care solution. Clin Infect Dis 29: 1281-1286.
Luk WK 1996. An outbreak of pseudobacteraemia caused by Burkholderia pickettii: the critical role of an epidemiological link. J Hosp Infect 34: 59-69.

Mandell WF, Garvey GJ, Neu HC 1987. Achromobacter xylosoxidans bacteremia. Rev Infect Dis 9: 1001-1005.

Manfredi R, Nanetti A, Ferri M, Chiodo F 1997. Bacteremia and respiratory involvement by Alcaligenes xylosoxidans in patients infected with the human immunodeficiency virus. Eur J Clin Microbiol Infect Dis 16: 933-938.

NCCLS-National Committee for Clinical Laboratory Standards 2003. Methods for dilution antimicrobial susceptibility test for bacteria that grow aerobically, 6th edition, Approved standard M7-A6, Wayne, PA.

NCCLS-National Committee for Clinical Laboratory Standards 2004. Performance standard for antimicrobial susceptibility testing. 14th Informational Supplement M100-S14. Wayne, PA.

Nordmann P, Poirel L, Kubina M, Casetta A, Naas T 2000. Biochemical-genetic characterization and distribution of OXA-22, a chromosomal and inducible class D beta-lactamase from Ralstonia (Pseudomonas) pickettii. Antimicrob Agents Chemother 44: 2201-2204.

Reverdy ME, Freney J, Fleurette J, Coulet M, Surgot M, Marmet D, Ploton C 1984. Nosocomial colonization and infection by Achromobacter xylosoxidans. J Clin Micro-biol 19: 140-143.

Roberts LA, Collignon PJ, Cramp VB, Alexander S, McFarlane AE, Graham E, Fuller A, Sinickas V, Hellyar A 1990. An Australia-wide epidemic of Pseudomonas pickettii bacteraemia due to contamined "sterile" water for injection. Med $J$ Aust 152: 652-655.

Sader HS, Jones RN 2005. Antimicrobial susceptibility of uncommonly isolated non-enteric gram-negative bacilli. Int $J$ Antimicrob Agents 25: 95-109.

Saiman L, Chen Y, Tabibi S, San Gabriel P, Zhou J, Liu Z, Lai L, Whittier S 2001. Identification and antimicrobial susceptibility of Alcaligenes xylosoxidans isolated from patients with cystic fibrosis. J Clin Microbiol 39: 3942-3945.

Vandamme P, Bernardet JF, Segers P, Kersters K, Holmes B 1994. New perspectives in the classification of the fla-vobacteria: description of Chryseobacterium gen. nov., Bergeyella gen. nov., and Empedobacter nom. rev. Int J Syst Bacteriol 44: 827-831.

Van Pelt C, Verduin CM, Goessens WH, Vos MC, Tummler B, Segonds C, Reubsaet F, Verbrugh H, Van Belkum A 1999. Identification of Burkholderia spp. in the clinical microbiology laboratory: comparison of conventional and molecular methods. J Clin Microbiol 37: 2158-2164.

Visalli M, Bajaksouzian AS, Jacobs MR, Appelbaum PC 1997. Comparative activity of trovafloxacin, alone and in combination with other agents, against gram-negative nonfermentative rods. Antimicrob Agents Chemother 41: 1475-1478.

Yabuuchi E. Kawamura Y, Kosako Y, Ezaki T 1998. Emendation of genus Achromobacter and Achromobacter xylosoxidans (Yabuuchi and Yano) and proposal of Achromobacter ruhlandii (Packer and Vishniac) comb. nov., Achromobacter piechaudii (Kiredjian et al.) comb. nov., and Achromobacter xylosoxidans subsp. denitrificans (Ruger and Tan) comb. nov. Microbiol Immunol 42: 429-438. 